\title{
Experiences and methodology in a multidisciplinary energy and architecture competition: Solar Decathlon Europe 2012
}

\author{
Iñaki Navarro Álvaro Gutiérrez Claudio Montero Edwin Rodríguez-Ubiñas \\ Eduardo Matallanas Manuel Castillo-Cagigal María Porteros Jorge Solórzano \\ Estefanía Caamaño-Martín Miguel A. Egido Jose M. Páez Sergio Vega
}

\begin{abstract}
A B S T R A C T
Solar Decathlon Europe is an international competition among universities which promotes interdisciplinary learning in engineering and architecture. Students from different disciplines participate in teams guided by several professors during a 29 month preparation period plus five weeks of on-site contest. The educational project involves designing, building and testing a solar energy house connected to the electrical grid with the strategy of maximizing self-consumption, supported by bioclimatic technologies and maintaining a low environmental footprint. It culminates in a on-site contest in which teams must assembly the house themselves, test it with ordinary real life tasks and finally disassembly it. The event has also a divulgative aim, trying to make students and visitors get interested in discovering the problems presented by real engineering and architecture applications. In addition, SDE covers R\&D aspects in different fields such as energy efficiency, solar energy and bioclimatic architecture. This article presents the methodology followed during the SDE 2012 edition, in which more than 850 students participated. The obtained results show that the educational competition was a success according to the technical and professional ambitions of the students, most of them considering that their knowledge had increased in areas related to technical and multidisciplinary aspects.
\end{abstract}

\section{Introduction}

During the last decades, working in interdisciplinary groups with common objectives is becoming a mandatory necessity in a wide variety of jobs [1]. University students must learn a great deal of specific knowledge, but they also need to develop their social capacity, professional abilities and innovation skills [2,3]. However, given the amount of courses and their limited time, it is sometimes very difficult to create interdisciplinary groups which mimic the future needs that students will find in their professional lives. Therefore, the development of activities that offer an opportunity of combining different knowledge branches, and that inspire and value students initiative and imagination, is a significant and unfortunately not very common contribution to university education [4]. Furthermore, university technical competitions can boost the motivation of students, who work in a real project learning not only a particular subject, but also teamwork skills, oral presentations and budget management $[5,6]$. In this manuscript, we present the experience of Solar Decathlon Europe (SDE) 2012, a university and multidisciplinary competition that aims to complement the students' education with these social and professional abilities required.

Solar Decathlon (SD) is an international competition among universities, created by the U.S. Department of Energy, which promotes research in the development of energy efficient houses [7-9]. The objective of the participating teams is to design and build houses that consume as few natural resources as possible and produce minimum waste products during their life cycle. Universities from all 
over the world meet to design, build and operate a solar energy home connected to the grid. Particular emphasis is put on reducing energy consumption and obtaining all the necessary energy from the sun. Therefore, every team participating in the competition must provide a multidisciplinary knowledge, including civil engineering, electrical engineering, computer science and architecture, among others $[10,11]$.

The first SD edition was held in 2002 [12] and the competition has since occurred biennially in 2005, 2007, 2009, and 2011 in its American version. SDE is the European version of this competition created through an agreement signed between the Spanish Ministry of Housing and the United States Government [13,14]. It is co-organized by Universidad Politécnica de Madrid. SDE has taken place in two editions celebrated in Madrid: SDE 2010 and SDE 2012. During the final phase of the competition, teams had to assemble their houses in Madrid, in a place open to the public with the possibility of visiting all the houses. SDE main aim is educational, trying to make people to get interested in discovering the problems presented by real engineering applications and architecture.

The experience accumulated in both editions has produced an exceptional tool for training professionals in the sector. This article aims to share the experience gained, describing the methodology, goals and structure of the competition.

The remainder of this article is organized as follows. In Section 2, the motivation of the competition and its different contests are explained. The methodology followed and different phases in which the competition was structured are described in Section 3. Section 4 presents the main results of the SDE including the participation, contest results and a survey answered by the participants. Finally, conclusions are described in Section 5.

\section{The competition}

SDE 2012 has a threefold purpose: educative, scientific and informative. Firstly, students involved in the project (decathletes) learn to work in multidisciplinary teams and how to face the challenges of the building-engineering future by developing innovative solutions. Moreover, it provides participating students with unique training that prepares them to enter in real work projects.

Secondly, universities and research centers have access to trying out scientific projects in real conditions to launch them later onto the market or by improving and using existing products in a creative way.

Thirdly, the general public can see and become aware of the real possibilities of reducing the environmental impact and at the same time keeping the comfort and quality of the design in their homes. It educates both students and the public about the money-saving opportunities and environmental benefits presented by clean-energy products and design solutions.

\subsection{Contest rules}

The contest is organized around 5 main areas (architecture, energy, comfort, social-economy and strategy) which are scored in 10 different contests awarded by a total of 1000 points (see Fig. 1). Some of the contests are evaluated by an external jury, while others depend on some specific tasks completion to be scored. Teams participating in the SDE 2012 competition should concentrate on every contest in order to obtain the maximum points. Hereafter, the 10 contests are described.

- Architecture: An attractive design is sought, which combines comfortable and functional spaces with bioclimatic technologies and strategies for reducing the houses energy consumption. A coherent and comprehensive project is desired.

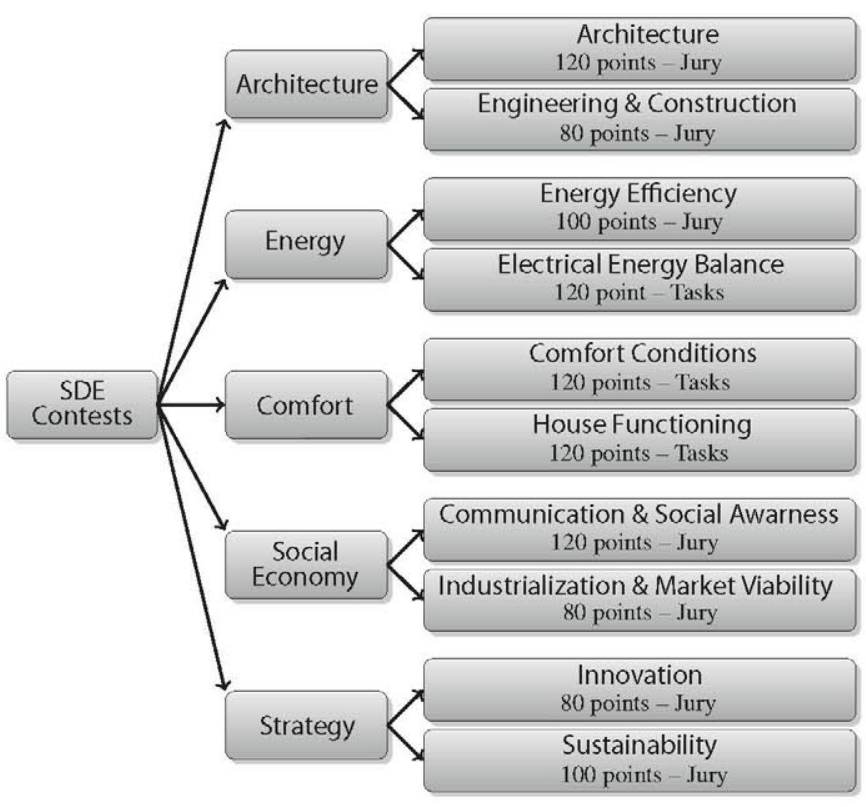

Fig. 1. SDE 2012 contest area organization sketch showing the different contests evaluated and their maximum number of points to be scored.

- Engineering and construction: This contest evaluates the appropriateness and commissioning of the systems used for the house construction and functioning. Elements ranging from the structure of the building to its solar systems are rated.

- Energy efficiency: The competition places special emphasis on teams covering house-dwellers' needs, using minimum possible resources. Concepts such as the building thermal envelope, active and passive systems (such as sunlight, ventilation, etc.) of thermal conditioning, efficiency of electrical appliances, control systems, and automation are evaluated.

- Electrical energy balance: This contest evaluates the capacity of the houses for electrical self-sufficiency. Houses should reduce consumption to a minimum and produce electricity in quantities equal or greater than their consumption.

- Comfort conditions: It evaluates each house capacity to maintain environmental conditions (temperature, humidity, acoustics, air quality and illumination) suitable for the comfort of its inhabitants.

- Functioning of the house: Checks are made on the possibility of performing normal everyday tasks, such as using electrical appliances (e.g., washing machine, dishwasher), electronic equipment (e.g., TV, DVD) and producing hot water.

- Communication and raising social awareness: This contest assesses teams ability to transmit to the public the basic concepts behind the SDE competition, as well as ideas contributed by their completed house along these lines, both during the period of prior design and during public visits. A jury of experts studies the communication plan designed by each team over the two years of development and takes the same house tour as that on offer to the public.

- Industrialization and market viability: This contest assesses whether the house can be successfully transferred onto the property market. Factors such as commercial appeal of the product, price of production and possibilities for prefabricating parts of the building and the design capacity for being adapted to other models of housing are evaluated.

- Innovation: Points are gained by teams who have made innovative solutions in various fields, ranging from architectural ideas to development of new materials and systems. 


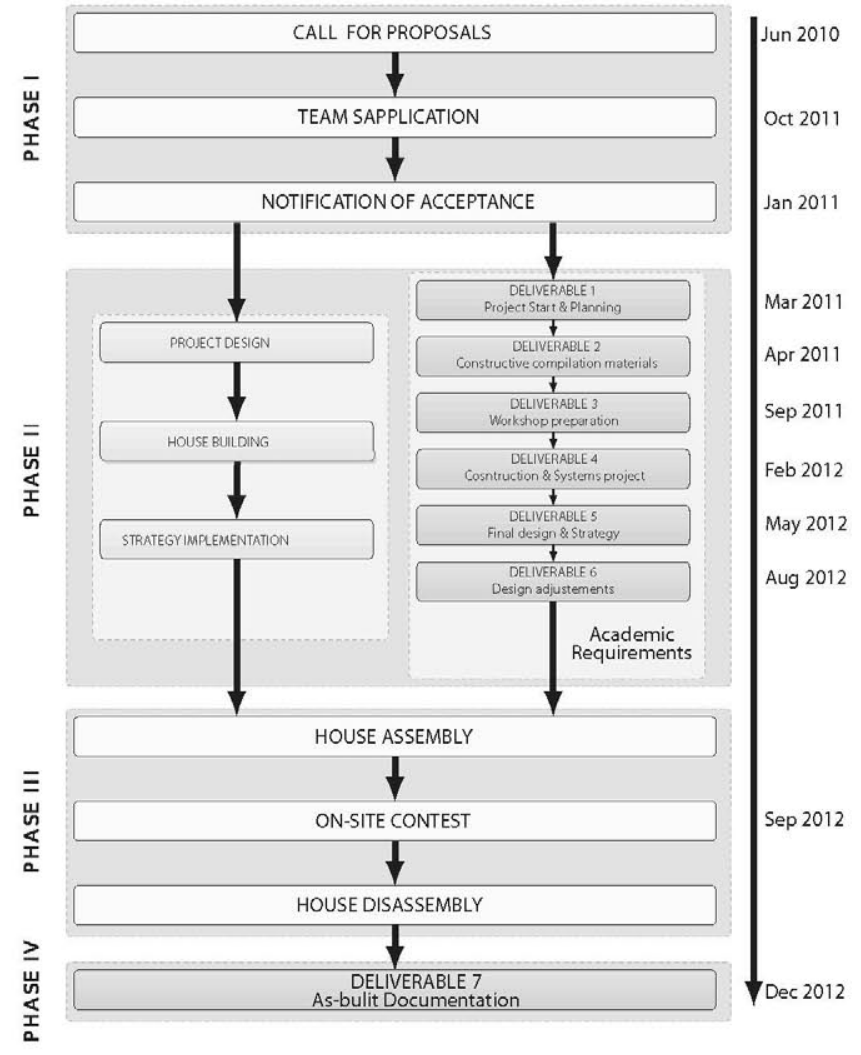

Fig. 2. SDE 2012 contest diagram.

- Sustainability: This contest considers the environmental impact of the house in its lifetime, from extraction and transformation of its materials, building procedures and use, to its demolition and recycling. Consideration is given to use of natural resources, possibilities for re-use and recycling, as well as to reduction in waste generation.

\section{Methodology and development}

SDE 2012 competition was scheduled for a 30 months period and structured in four main phases (see Fig. 2). Hereafter, these phases and their goals are described.

\subsection{Phase I: teams application and selection}

From June to October 2010, post-secondary educational institutions around the world, mainly universities were able to apply for the competition. In total 33 team proposals from 47 universities and 18 countries were received. 20 teams where selected in January 2011 to participate in the competition. Three more proposals were selected as exhibition teams which would enter in competition in the case that some main teams were not able to participate. They were selected according to the following selection criteria:

- Technical innovation and design (25\%): The conceptual design should address building-integrated photovoltaics, feasibility of the design, scientific/technical quality, soundness of the analysis, trade-offs, and design approach. Industrialization and marketability of the prototype and conditions for sharing of knowledge should also been addressed, as well as environmental, safety, and health considerations for the construction and competition phases, including assembly and disassembly. Multidisciplinary teams (e.g., between engineering, architecture, design and communications) are strongly encouraged.
- Curriculum integration and special considerations (25\%): Because of the educational objective of SDE 2012, candidates must maximize the educational benefits of the project. Therefore, the project should be integrated into the students' course works. Moreover, the proposal should incorporate special considerations, that deserve extra merit, such as research projects, technical innovation and creativity, or new ideas that will make the project more likely to succeed.

- Organization and project planning (25\%): Being a complex project, a thorough organization and planning are mandatory. Activities must be planned and organized adequately to ensure successful completion, such as who will make decisions, how conflicts will be solved or how the house will be transported, assembled and disassembled.

- Fund raising and team support (25\%): Being a 30 months project, involving an average of 50 participants per team, plus the building, transportation, assembling and disassembling of a functional house, it is essential that a complete budget is presented in the proposal. It should give a clear understanding of the costs associated with the project and the need for fund raising where the level of available or obtainable equipment, instrumentation, and facilities are presented.

\subsection{Phase II: pre-contest requirements}

In this phase previous to the on-site contest, different deliverables were requested to every team in order to evaluate the on-going project, and ensure a fruitful participation during the onsite contest.

- Deliverable 1 (March 2011): Its primary objective was to verify the work that the teams were generating among the various fields to develop in the project. It was also designed to identify, as soon as possible, any aspect or design which would not fit or match with the sense of the competition.

- Deliverable 2 (April 2011): It was intended to compile materials from every participant team, in order to start organizing different events and activities, to contribute to the SDE goal of disseminating knowledge and project diffusion.

- Deliverable 3 (September 2011): At this stage of the competition projects must include an extensive description of the project details and specifications, of the materials, constructive systems, equipment, footing, structural and trades report, and detailed drawings. Teams should have considered all remarks made by the SDE Organization in Deliverable 1. This deliverable was used to prepare a workshop held in October 2011 in Madrid. The workshop consisted on multiple meetings between the SDE Organization and the teams in order to clarify the status of their projects and future actions.

- Deliverable 4 (February 2012): It aims to provide all the necessary information in order to define the construction of the Villa Solar (neighborhood composed by the competing houses) and to foresee every element required for that purpose.

- Deliverable 5 (May 2012): Its objective was to obtain additional information and update the documentation sent in Deliverable 4 based on the requirements made by the SDE Organization from the last deliverable, including changes and design adjustments.

- Deliverable 6 (August 2012): Design adjustments were opened to the teams in case there was any change in the project before contest and should be included in this deliverable. It provided the juries with relevant and detailed information about the projects, given limited opportunity they had to evaluate the constructed projects. 


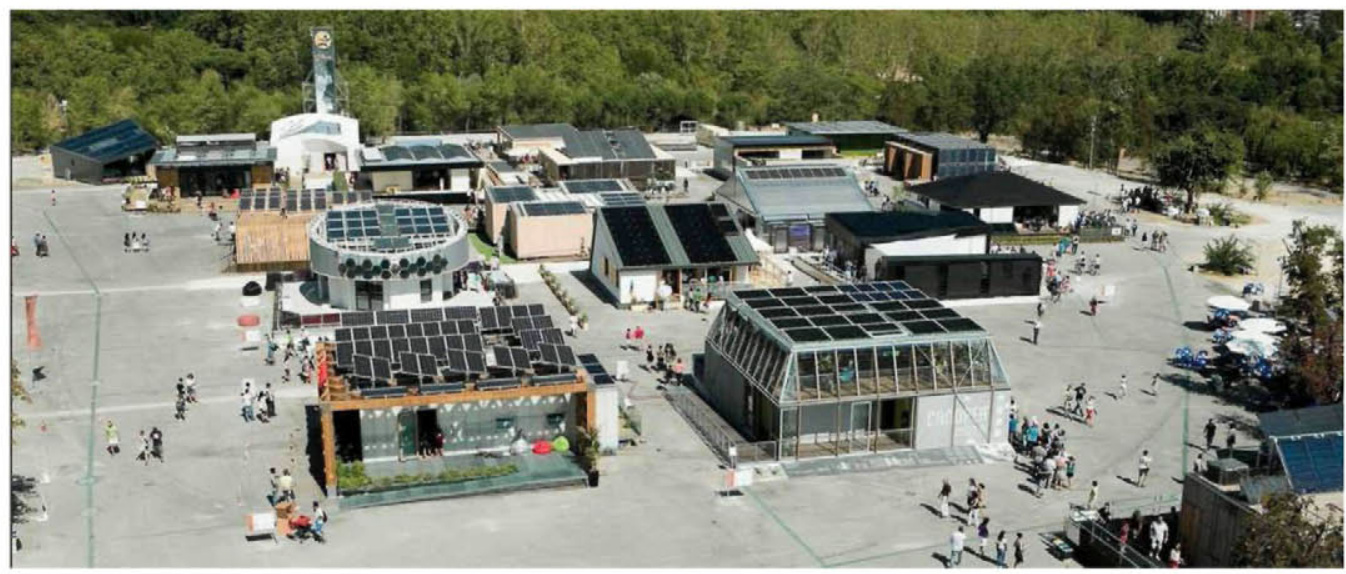

Fig. 3. SDE 2012 Villa Solar overview at Madrid.

\subsection{Phase III: on-site contest}

On-site contest was held from August 31st to October 5th (see Fig. 3), divided in the following activities:

- Assembly: From August 31st to September 12th, the teams had to build their houses at the Villa Solar location. During assembly, inspectors were in charge of checking that everything was implemented according to the teams projects, and ensuring safety according to the national standards.

- Contest: Two weeks of contest were scheduled from September 17 th to September 28th. The main core of the contest period involved the jury and automated measurements process [15] from 8:00 to 23:00. However, an every day $4 \mathrm{~h}$ period, from 16:00 to 20:00, was scheduled for public visits. Within this period, no automated measurements were involved and teams had to explain their house construction and functioning to the general public. Moreover, daily and specially during the weekend, specific activities were scheduled, including solar energy games for kids, technical workshops for students, scientific conferences from the teams and industry sponsors.

- Public visits: Exclusive public visits were held in September 13th, 14th, 15th, 16th, 22nd, 23rd, 29th and 30th.

- Disassembly: October 1st-5th, houses had to be disassembled, ensuring, as during the construction process, safety.

\subsection{Phase IV: post-contest requirements}

This phase consisted on writing and submitting the final deliverable of the competition.

- Deliverable 7 (December 2012): Its objective was to have the as-built drawings and specifications of the participating houses, with an extensive description of the details and specifications of the materials, PV systems, constructive systems, house automation systems, equipment, structure, plumbing, HVAC, etc. It had also to reflect teams strategy during the on-site contest weeks. The as-built technical data of the houses, its construction drawings and project manuals can be found at SDE 2012 web site. ${ }^{1}$ This information helps students and professionals, from around the world, to get a deeper knowledge about the strategies and technical solutions used in the participants houses.

\section{Results}

\subsection{Participation}

As already mentioned in Section 3, 20 main (and 3 exhibition) teams were selected in January 2011 to enroll in the project and attend the competition. However, only 18 teams finally participated in phase III because of planning and financial issues. Therefore, all information presented in this section is related to the 18 teams finally participating in the on-site contest.

For these teams, a total of 862 decathletes were involved in the competition. Around one-third of them were females (see Fig. 4a). The background profiles were shared between engineers (28\%) and architects (63\%) (see Fig. 4b). Moreover, nearly half of the decathletes (47\%) were MSc students, one-third (30\%) BSc students and the rest was divided between $\mathrm{PhD}$ students, post-doctoral researchers, professors and others (see Fig. 4c). Nonetheless, more than half of the decathletes (60.5\%) were involved in some research work related to the SDE 2012 (see Fig. 4d) and approximately half (48.5\%) of them were doing their MSc or $\mathrm{PhD}$ or thesis in relation to SDE 2012 (see Fig. 4e).

\subsection{Contest results}

Scoring and team ranking of the on-site contest are presented in Table $1 .^{2}$ The top of the table is dominated by only four teams, who share the first position for all contests. Moreover, only five teams obtained $80 \%$ of the total points and only the first one was able to exceed $90 \%$ of the total points. Nonetheless, the difference between the first and second place was only of 11.33 points (1.13\% of total points).

However, given the economical difference between the teams it is important to take into account the relative scoring with respect to the number of members and budget of every team. Fig. 5 shows the relationship between the budget, scoring and size of the team. Notice that first team in the ranking (R01) is the one with a higher budget $(\sim 2.7 \mathrm{M} €)$ but with a moderate number of decathletes $(\sim 50)$. On the other hand, the fifth team (R05) in the ranking was made up of 96 members with a more moderate budget $(\sim 1.5 \mathrm{M} €)$. Nonetheless, it is important to state that last two teams in the classification ( $R 17$ and $R 18$ ) were both coming from the exhibition list. They were offered to participate in the competition 6 months prior to on-site contest, resulting in a very difficult situation for sponsorship and technical development. 
(a) Gender ratio of decathletes

Male

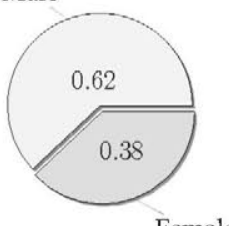

(b) Professional background of decathletes

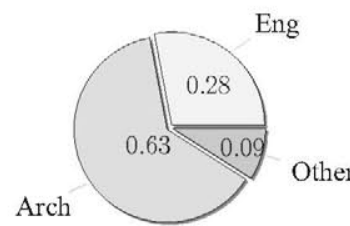

(c) Professional degree of decathletes

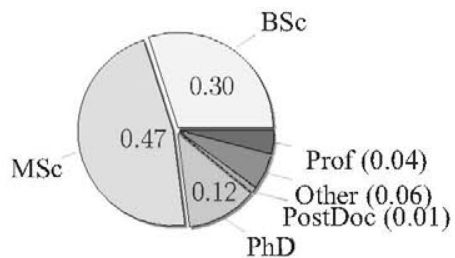

(d) Research involvement of decathletes

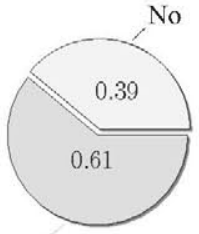

Yes (e) Enrollment in related $\mathrm{MSc}$ or $\mathrm{PhD}$ thesis

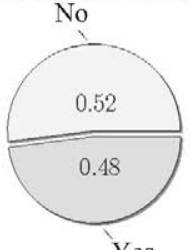

Fig. 4. Summary of participation.

Table 1

Solar Decathlon 2012 contest scoring. Bold values show the best rank for each contest.

\begin{tabular}{|c|c|c|c|c|c|c|c|c|c|c|c|c|}
\hline Rank & $\mathrm{C} 1$ & $\mathrm{C} 2$ & $\mathrm{C} 3$ & C4 & $\mathrm{C} 5$ & C6 & C7 & C8 & $\mathrm{C} 9$ & $\mathrm{C} 10$ & Bonus & Total \\
\hline 1 & 120.00 & 71.00 & 87.00 & 87.11 & 114.86 & 116.85 & 77.30 & 72.90 & 75.00 & 86.70 & 0.00 & 908.72 \\
\hline 2 & 95,00 & 73.00 & 100.00 & 106.51 & 92.86 & 110.32 & 80.00 & 64.90 & 68.90 & 95.90 & 10.00 & 897.39 \\
\hline 3 & 100.00 & 72.00 & 87.00 & 93.87 & 96.46 & 115.85 & 66.70 & 64.00 & 57.60 & 100.00 & 10.00 & 863.49 \\
\hline 4 & 95.00 & 80.00 & 93.00 & 72.79 & 95.37 & 113.93 & 56.00 & 80.00 & 54.70 & 86.70 & 7.50 & 835.00 \\
\hline 5 & 110.00 & 59.00 & 87.00 & 72.63 & 82.48 & 113.00 & 66.70 & 71.10 & 55.60 & 91.80 & 10.00 & 819.31 \\
\hline 6 & 70.00 & 77.00 & 93.00 & 70.96 & 109.05 & 106.17 & 54.80 & 54.20 & 42.10 & 86.70 & 3.00 & 766.98 \\
\hline 7 & 95.00 & 66.00 & 80.00 & 95.44 & 85.47 & 100.67 & 60.70 & 48.90 & 44.20 & 81.60 & 8.00 & 765.98 \\
\hline 8 & 95.00 & 67.00 & 53.00 & 87.15 & 102.93 & 104.69 & 44.40 & 71.10 & 35.00 & 66.30 & 5.00 & 731.57 \\
\hline 9 & 50.00 & 68.00 & 97.00 & 90.61 & 97.06 & 108.00 & 60.70 & 55.10 & 13.30 & 71.40 & 8.00 & 719.16 \\
\hline 10 & 60.00 & 65.00 & 75.00 & 83.93 & 96.80 & 106.36 & 51.80 & 64.90 & 32.90 & 71.40 & 7.50 & 715.59 \\
\hline 11 & 70.00 & 46.00 & 63.00 & 79.73 & 105.24 & 114.91 & 59.30 & 48.00 & 32.40 & 66.30 & 2.00 & 686.88 \\
\hline 12 & 70.00 & 58.00 & 57.00 & 73.50 & 91.61 & 111.10 & 44.40 & 63.10 & 31.00 & 76.50 & 8.00 & 684.20 \\
\hline 13 & 70.00 & 60.00 & 57.00 & 86.80 & 94.25 & 92.35 & 48.90 & 55.10 & 28.90 & 76.50 & 5.00 & 674.80 \\
\hline 14 & 60.00 & 54.00 & 68.00 & 70.91 & 99.32 & 85.86 & 62.20 & 49.80 & 27.10 & 91.80 & 2.00 & 670.99 \\
\hline 15 & 50.00 & 71.00 & 68.00 & 63.77 & 96.56 & 111.68 & 59.20 & 33.80 & 37.70 & 61.20 & -11.00 & 641.91 \\
\hline 16 & 40.00 & 49.00 & 45.00 & 84.33 & 66.85 & 102.11 & 38.50 & 49.80 & 30.20 & 51.00 & -18.50 & 538.29 \\
\hline 17 & 40.00 & 32.00 & 45.00 & 31.78 & 64.33 & 77.88 & 32.50 & 17.80 & 19.10 & 56.10 & 0.00 & 416.49 \\
\hline 18 & 30.00 & 34.00 & 45.00 & 12.82 & 62.78 & 67.08 & 37.00 & 13.30 & 23.40 & 56.10 & -10.00 & 371.48 \\
\hline
\end{tabular}

\subsection{Project evaluation}

Being in an outstanding multidisciplinary education project which involves the work of students, it is mandatory to evaluate the project itself, from the decathletes perspective. For this purpose the SDE 2012 organization launched a poll with different questions to be evaluated and answered by the decathletes. 310 decathletes out of 862 replied to the poll. Questions were divided in three main blocks and decathletes answers are presented in Fig. 6:

- Technical education: about the understanding of the construction process, sustainable build environment, home automation systems and solar energy systems.
- Professional skill development: about the communication, multi-disciplinary work, reality and professional and ethical responsibilities.

- Competition evaluation: About the competition itself, e.g., organization, rules, etc.

By studying the answers it can be observed that the competition has been a success from the technical and professional ambitions of the decathletes. A vast majority considers that knowledge has been increased very much in most areas related to technical and multidisciplinary aspects of the SDE 2012. Rating about the competition and the organization itself is more than positive, although the most disagreement is found with the competition rules. This mid-upper rating may be due to disagreement in the

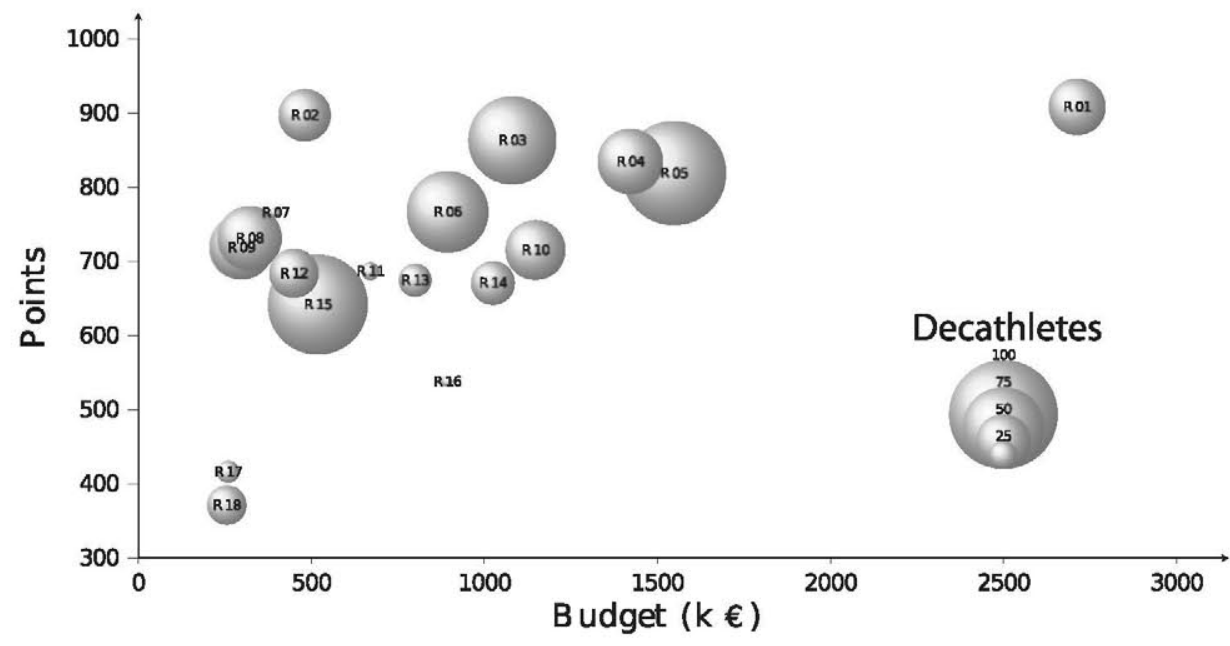

Fig. 5. SDE 2012 contest results ( $Y$ axis) relative to the budget ( $X$ axis) and teams size (circle dimensions). 
(Q1) Has SDE2012 helped you to gain a better understanding of the construction process and the facilities in buildings? [1 (Nothing) - 5 (Very much)]

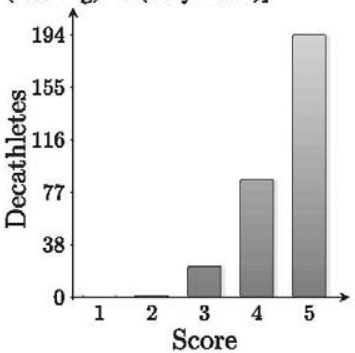

(Q5) Has SDE2012 helped you to improve your communication skills? [1 (Nothing) - 5 (Very much)]

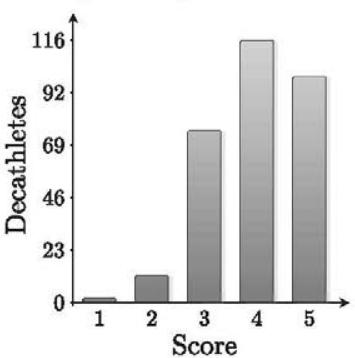

(Q) Rate SDE2012 organization [1 (Bad) - 5 (Excellent)].

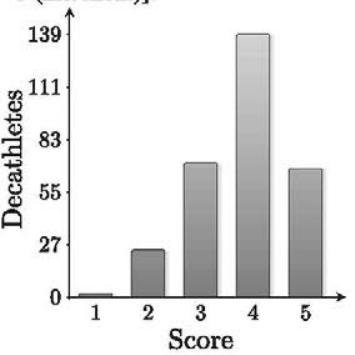

(Q2) Has SDE2012 helped you to gain a better understanding of sustainable build environment? [1 (Nothing) - 5 (Very much)]

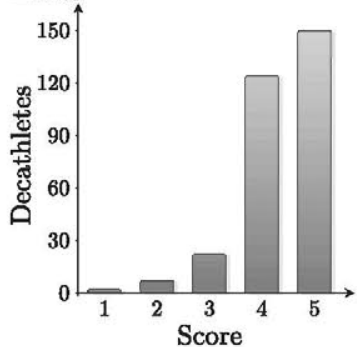

(Q3) Has SDE2012 helped you to gain a better understanding of home automation? [1 (Nothing) - 5 (Very much)]

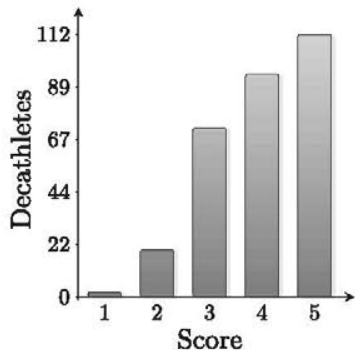

Professional skill development

(Q6) Has SDE2012 helped you to improve your ability to work on multidisciplinary teams? [1 (Nothing) - 5 (Very much)]

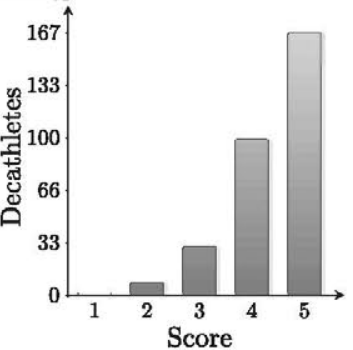

(Q7) Has SDE2012 helped you to develop your ability to make decisions based on realistic conditions? [1 (Nothing) - 5 (Very much)]

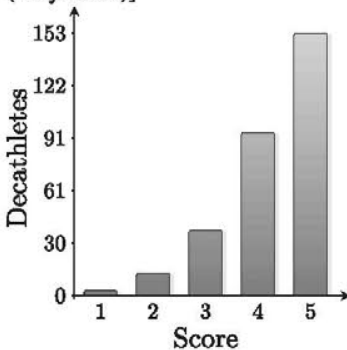

Competition

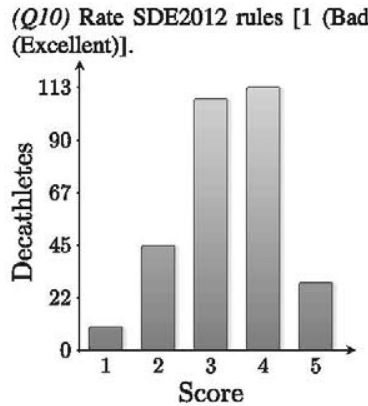

(Q4) Has SDE2012 helped you to gain a better understanding of solar energy systems? [1 (Nothing) - 5 (Very much)]

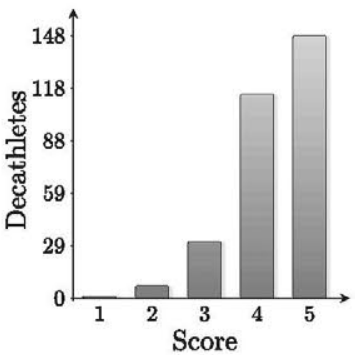

(Q8) Has SDE2012 helped you to gain a better understanding of professional and ethical responsibility? [1 (Nothing) - 5 (Very much)]

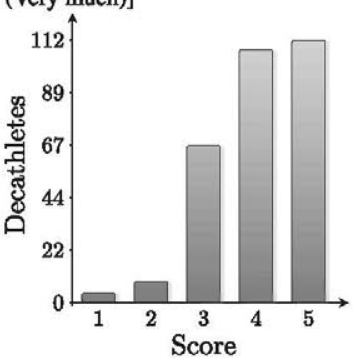

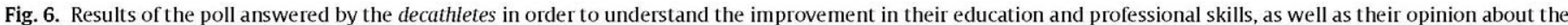
competition.

points distribution depending on the decathletes profiles. However, the overall experience of the competition is stated mainly as excellent.

\section{Conclusions}

In this article, we have presented Solar Decathlon Europe 2012, an educational project-based competition. The main aim of the competition is educational and we think given the poll results that it was fulfilled. Students improved their ability to work in interdisciplinary groups, developing their scientific, technical and social abilities and were very motivated on their work. The competition entailed more than 862 students, half of them being involved in the project with research and MSc or PhD thesis. Feedback from the participation of decathletes is positive both from the educational perspective and the project itself.

For future editions, bigger efforts must be done for a complete agreement on the competition rules and objectives, although the assessment of the overall experience is very positive and allows an excellent starting point.

Furthermore, behavior of teams related to the solar energy production and consumption were very efficient with positive exchange (nearly double energy produced than consumed) of electricity from the houses to the electricity grid.

The learnt experiences have allowed a better understanding of multidisciplinary areas such as architecture, solar energy or home automation. In addition, the data collected during the contest regarding solar energy and passive and active systems will allow for future analysis of this information and the advance in several research related topics.

Finally, the public visits to the on-site contest were a complete success. The Villa Solar received over 220,000 visits, 64,094 of which were guided tours. Moreover, 2000 university students, 6000 professionals and 5000 children attended the different activities planned according to their profile. Visitors learned about the importance of energy efficiency, insulation and the use of renewable energies. 


\section{Acknowledgements}

E. Matallanas is sponsored by the Spanish Ministry of Education with a PhD grant (FPU-2011). M. Castillo-Cagigal is sponsored by the Spanish Ministry of Education with a PhD grant (FPU-2010). J. Solórzano thanks the Fundación Iberdrola (F. Iber 2013) for the awarded grant for his PhD studies during the 2012-2013 academic year. This work has been partly funded by the Spanish Science and Innovation Ministry under the IPT-2011-1468-920000 grant and the Economy and Competitiveness Ministry under the IPT-20121072-120000 grant.

\section{References}

[1] S. Benay, M. Fernandez, M. Thursby, Implications of a multidisciplinary educa tional and research environment: perspectives of future business, law, science and engineering professionals in the technological innovation: generating economic results (TI:GER) program, Technology Analysis and Strategic Management 18 (1) (2006) 57-69.

[2] S.D. Eppinger, M.S. Kressy, Interdisciplinary product development education at MIT and RISD, Design Management 13 (3) (2002) 58-61.

[3] European Commission, Europe's Universities must be Modernized, Says Commission, Tech. Rep., Europe Press Release, Luxembourg, 2006.

[4] F. Gider, B. Likar, T. Kern, D. Miklavcic, Implementation of a multidisciplinary professional skills course at an electrical engineering school, IEEE Transactions on Education 55 (3) (2012) 332-340.

[5] P. Gregson, T. Little, Using contests to teach design to EE juniors, IEEE Transactions on Education 42 (3) (1999) 229-232, doi:10.1109/13. 779906.

[6] M. Hernando, R. Galan, I. Navarro, D. Rodriguez-Losada, Ten years of cybertech: the educational benefits of bullfighting robotics, IEEE Transactions on Education 54 (4) (2011) 569-575, http://dx.doi.org/10.1109/TE.2010.2095014.
[7] R.J. King, C. Warner, Solar decathlon: energy we can live with, in: Proceedings of the 3rd World Conference on Photovoltaic Energy Conversion, IEEE Press, Piscataway, NJ, 2003, pp. 2139-2142.

[8] M.R. Wassmer, M.J. Brandemuehl, A. Jackaway, The simulation of a zero-energy residential building for the solar decathlon competition, in: Proceedings of the International Solar Energy Conference, American Society of Mechanical Engineers, New York, NY, 2003, pp. 45-53.

[9] C.L. Warner, M.R. Wassmer, Solar decathlon 2005 - PV system strategies and results, in: Proceedings of the 4th World Conference on Photovoltaic Energy Conversion, IEEE Press, Piscataway, NI, 2006, pp. 2272-2276.

[10] C.L. Warner, R. King, R. Nahan, M. Eastment, Solar decathlon: colle giate challenge to build the future, in: Proceedings of the 29th IEEE Photovoltaic Specialists Conference, IEEE Press, Piscataway, NJ, 2002, pp. $44-48$.

[11] E.A. Holt, B. Loss, M. Shaurette, Students involvement in the solar decathlon competition: giving context to the classroom experience, in: Proceedings of the 48th ASC Annual International Conference, Associated Schools of Construction, Birmingham, UK, 2012, pp. 1-7.

[12] S. Hayter, R. Nahan, B. Stafford, C. Warner, E. Hancock, R. Howard, Solar Decathlon 2002: The Event in Review, U.S. Dept. of Energy, Energy Efficiency and Renewable Energy, Washington, 2004.

[13] C.L. Warner, S. Farrar-Nagy, M. Wassmer, B. Stafford, R. King, S. Vega-Sanchez, E. Rodriguez-Ubiñas, J. Cronemberger, J.S. María-Tomé, The 2009 Department of Energy Solar Decathlon and the 2010 European Solar Decathlon - expanding the global reach of zero energy homes through collegiate competitions, in: Proceeding of the 34th Photovoltaic Specialists Conference, IEEE Press, Piscataway, N., 2009, pp. 002121-002125.

[14] Y. Xiangqun, G. Hui, Energy and environment strategies of a Chinese prototype of solar house: introduction of an entry of the SDE 2010 competition, in: Proceedings of the International Conference on Computer Distributed Control and Intelligent Environmental Monitoring, IEEE Press, Piscataway, NJ, 2011, pp. $1482-1486$.

[15] M. Castillo-Cagigal, E. Matallanas, A. Gutiérrez, F. Monasterio-Huelin, E. Caamaño-Martín, D. Masa-Bote, J. Jiménez-Leube, Heterogeneous collaborative sensor network for electrical management of an automated house with PV energy, Sensors 11 (12) (2011) 11544-11559. 